\title{
PERAN PEMBELAJARAN HOMESCHOOLING DALAM MEMBENTUK KECERDASAN INTRAPERSONAL
}

\author{
(Studi di Fikar School Rempoa, Tangerang Selatan)
}

\author{
Monica Nur Azizah \\ Siti Shopiyah, MA \\ Institut Ilmu Al-Qur'an Jakarta \\ monica76@gmail.com \\ s.shofiyah71@yahoo.com
}

\begin{abstract}
The background of the authors conducted this research because homeschooling is a home-based education, which allows children to develop according to their own potential. Homeschooling is also a choice that is considered appropriate to provide instruction for gifted children by many parents because the content of learning materials and the way they are provided are adjusted to the circumstances of the students concerned. At Fikar School, we implement community-based homeschooling and have interesting and effective learning methods. Based on the background of the problem, the authors are interested in knowing the role of homeschooling learning in shaping intrapersonal intelligence at Fikar School Rempoa, South Tangerang. The research method used in this research is a descriptive analysis research, by describing the actual situation or facts according to what happened in the field. The approach used is a qualitative approach, with research stages namely observation, interviews, and documentation. Then this study uses data analysis techniques namely data reduction, data presentation and drawing conclusions. his can be proven by the results of the study, namely that at Fikar School strongly applies to the character content of children and it impacts on each child to be able to know the extent of their abilities and awareness of their interests and talents. With a learning process such as this culture habit, it can have a good influence on a child's intrapersonal intelligence, so that it can form good character and make the child's culture to be independent wherever the environment.
\end{abstract}

Keywords: Homeschooling, Intrapersonal Intelligence

\begin{abstract}
ABSTRAK
Latar belakang penulis melakukan penelitian ini karena homeschooling merupakan pendidikan berbasis rumah, yang memungkinkan anak berkembang sesuai dengan potensi diri mereka masing-masing. homeschooling juga menjadi pilihan yang dianggap tepat untuk memberikan pengajaran bagi anak-anak yang berbakat oleh banyak orangtua karena konten materi pembelajaran dan cara pemberian materinya disesuaikan dengan keadaan siswa yang bersangkutan. Di Fikar School ini menerapkan homeschooling berbasis komunitas dan mempunyai metode pembelajaran yang menarik dan efektif. Berdasarkan latar masalah tersebut, penulis tertarik untuk mengetahui peran pembelajaran homeschooling dalam membentuk kecerdasan intrapersonal di Fikar School Rempoa, Tangerang Selatan. Metode penelitian yang digunakan dalam penelitian ini adalah penelitian yang bersifat deskriptif analisis, dengan menguraikan keadaan atau fakta yang sebenarnya sesuai yang terjadi di lapangan. Pendekatan yang digunakan yaitu pendekatan kualitatif, dengan tahapan penelitian yaitu observasi, wawancara, dan dokumentasi. Kemudian penelitian ini menggunakan teknik analisis data yaitu reduksi data, penyajian data dan penarikan kesimpulan/verifikasi. Hal ini dapat dibuktikan dengan hasil penelitian, yaitu bahwa di Fikar School sangat menerapkan pada muatan karakter anak dan itu berdampak kepada diri masing-masing anak tersebut untuk dapat mengetahui sejauh mana kemampuan yang dimiliki dan kesadaran akan minat dan bakat mereka. Dengan proses pembelajaran seperti culture habit ini dapat memberikan pengaruh yang baik kepada kecerdasan intrapersonal anak, sehingga dapat membentuk karakter yang baik dan menjadikan budaya anak untuk mandiri di manapun lingkungan dia berada.
\end{abstract}

Kata Kunci: Homeschooling, Kercerdasan Intrapersonal. 


\section{A. Latar Belakang Masalah}

Antara pendidikan di sekolah, keluarga, dan masyarakat terdapat saling keterkaitan. Di satu sisi, karena pendidikan adalah bagian dari kehidupan yang dituntut mampu mengikuti perkembangan di dalamnya. Di pihak lain, karena misi yang diemban pendidikan tidak larut dalam pengaruh lingkungan sekitarnya. Pendidikan, dalam hal ini, tidak diharapkan hanya menjadi buih karena gelombang perkembangan zaman. Berdasarkan nilai-nilai yang diidealkan, pendidikan akan selalu berupaya menjalani kehidupan.

Dalam sejarah perkembangan peradaban manusia, bukanlah taken for granted, tetapi jauh sebelumnya telah mengalami suatu proses yang panjang yakni melalui "belajar", "pendidikan", dan "pengalaman" tersendiri berdasarkan zamannya. Mereka mungkin tidak sekolah secara "formal" di sekolah, tetapi mereka belajar dari pengalaman. Proses belajar dan pendidikan yang dialami mereka dalam zaman yang berbeda tersebut telah menjadikan manusia mampu memenuhi kebutuhan, menjalani kehidupan hingga memasuki zaman peradaban seperti sekarang ini. ${ }^{1}$

Terhadap permasalahan pendidikan, sering kali hanya mengartikannya secara sempit dan belum mengangkatnya ke dalam cakupan yang lebih luas. Padahal tanpa memperhatikan dimensi makro seperti kekuatan ekonomi, politik, dan birokrasi yang berkembang, masalah besar yang sifatnya mendasar dalam proses pendidikan sulit tersentuh. Bertalian dengan tantangan perkembangan zaman pada masyarakat modern, sumber daya manusia (human power) sering diabaikan yang seharusnya dipersiapkan. Padahal SDM yang unggul terbukti lebih menentukan kemajuan suatu masyarakat. ${ }^{2}$

Dalam pasal 3 Undang-Undang Republik Indonesia Nomor 20 Tahun 2003 tentang Sistem Pendidikan Nasional dikatakan:

Pendidikan nasional berfungsi mengembangkan kemampuan dan membentuk watak serta peradaban bangsa yang bermartabat dalam rangka mencerdaskan kehidupan bangsa, bertujuan untuk berkembangnya potensi peserta didik agar menjadi manusia yang beriman dan bertakwa kepada Tuhan Yang Maha Esa, berakhlak mulia, berilmu, cakap, kreatif, mandiri, dan menjadi warga negara yang demokratis serta bertanggung jawab. $^{3}$

Dari ketentuan pemerintah tentang Sistem Pendidikan Nasional di atas, maka antara pendidikan dan perkembangan masyarakat tidak dapat dipisahkan satu sama lain. Kemajuan suatu masyarakat dan suatu bangsa sangat ditentukan pembangunan sektor pendidikan dalam penyiapan Sumber Daya Manusia (SDM) yang sesuai dengan perkembangan zaman. Sumber Daya Manusia bangsa Indonesia ke depan tidak terlepas dari fungsi pendidikan nasional.

Dalam kehidupan sehari-hari, pertumbuhan anak dapat kita saksikan dari perubahan terutama pada fisik anak, yaitu dari yang semula bayi, yang kecil setelah mengalami masa pertumbuhan dalam kurun waktu tertentu menjadi besar dan pada akhirnya nanti akan menjadi tua dan meninggal. Seiring pertumbuhan fisik pada anak juga terjadi

\footnotetext{
${ }^{1}$ Abdullah Idi, Sosiologi Pendidikan, (Jakarta: PT. Raja Grafindo Persada, 2014), hlm. 59

${ }^{2}$ Abdullah Idi, Sosiologi Pendidikan, ..., hlm. 60

${ }^{3}$ Undang-Undang Republik Indonesia nomor 20 Tahun 2003 tentang Sistem Pendidikan Nasional, Bab II, Pasal 3

2 |Monica Nur Azizah dan Siti Shopiyah: Peran Pembelajaran Home Schooling, ...
} 
perkembangan pada mentalnya. Sewaktu masih bayi, ia belum bisa berpikir sempurna tetapi setelah menjadi manusia dewasa pikirannya menjadi lengkap sampai mendekati kesempurnaan yang tinggi. ${ }^{4}$

Lingkungan adalah faktor yang turut menentukan tumbuh kembang anak. Perumahan yang layak, terutama dalam hal sanitasinya, cukup leluasa, dan bebas polusi bagi anak untuk bermain memberi peluang tumbuh kembang anak dengan lebih baik. Sebaliknya, lingkungan yang kotor dan sempit serta tiada ketersediaan ruang bermain bagi anak dapat menghambat proses tumbuh kembang anak. Anak yang mengalami hambatan tumbuh kembang akan berpengaruh pada ketidaklancaran anak dalam menyerap pendidikan. Jadi, lingkungan tempat tinggal anak tidak dapat dikesampingkan begitu saja agar anak mengalami tumbuh kembang secara baik. ${ }^{5}$

Interaksi sosial bersifat positif dapat menciptakan terjadinya kerjasama yang pada akhirnya mempermudah terjadinya pembauran. Proses sosial adalah aspek dinamis dari kehidupan masyarakat, di dalamnya terdapat suatu proses hubungan antara manusia satu dengan lainnya. Proses hubungan tersebut berupa interaksi sosial yang terjadi dalam kehidupan sehari-hari secara terus-menerus. ${ }^{6}$

Orang tua dipersepsikan mempunyai peran penting dalam mendidik anak-anaknya karena dasar pemikirannya sebagai berikut: tidak ada yang lebih mengetahui kecuali orangtua tentang kekuatan dan kelemahan anak-anaknya, keberhasilan dan kegagalan, suka cita atau keputusasaan anak-anaknya. Mulai bayi waktu belajar makan, belajar berjalan, menghormati orang yang lebih tua dan lebih banyak lagi, hanya orang yang mengajari keterampilan dan perilakunya. Orang tua adalah guru bagi anak-anaknya dan orang paling berharga bagi anak-anaknya. Tuntutan sebagai guru di homeschooling bukan tingkat pendidikan formal, bukan sertifikat profesional guru, tetapi kemampuan alami untuk memelihara, membesarkan, dan menanamkan semangat serta kecintaan untuk belajar pada anak-anaknya. Pendidikan yang dilakukan orangtua kepada anak-anaknya sebagai bagian yang alami dari kehidupan. ${ }^{7}$

Belakangan ini, istilah homeschooling mulai akrab di kalangan telinga masyarakat. Homeschooling di Indonesia sering dikaitkan dengan selebritas, yang karena kesibukannya akhirnya lebih memilih keluar dari sekolah formal dan menjalani homeschooling. Sebenarnya, homeschooling tidak hanya dijalani oleh orang ternama. Dan alasannya pun bukan semata karena tidak bisa menjalani karier dan sekolah secara bersamaan. Homeschooling dapat dilakukan oleh semua orang tanpa terkecuali, namun hanya akan berhasil bagi orang-orang yang memiliki disiplin dan memegang komitmen yang kuat. Itu syarat utamanya.

Sesungguhnya homeschooling tidak hanya menyuguhkan pengetahuan yang sempit terbatas di dalam "kerangka kurikulum". Tapi penyelanggaraan homeschooling meluas hingga mencakup segala aspek pendidikan yang dibutuhkan seseorang untuk bekal hidup, education for life. Dengan kerangka pendidikan yang seperti ini, homeschooling

${ }^{4}$ Purwa Atmaja Prawira, Psikologi Pendidikan Dalam Perspektif Baru, (Jogjakarta: Ar-Ruzz Media, 2012), hlm. 86

${ }^{5}$ Purwa Atmaja Prawira, Psikologi Pendidikan Dalam Perspektif Baru, ..., hlm. 78

${ }^{6}$ Abdullah Idi, Sosiologi Pendidikan, ..., hlm. 82

${ }^{7}$ Seto Mulyadi dkk., Psikologi Pendidikan, (Depok: PT. Raja Grafindo Persada, 2017), hlm. 86 3 |Monica Nur Azizah dan Siti Shopiyah: Peran Pembelajaran Home Schooling, ... 
menyejajarkan pendidikan akademis dan pendidikan karakter. Sepandai apapun seseorang secara akademis, tapi jika karakter yang dimiliki tidak mendukung pengembangan dirinya, maka akan sulit baginya untuk terjun baik ke dalam dunia pekerjaan maupun dalam bermasyarakat. ${ }^{8}$

Dengan menjadi bagian dari kegiatan mendidik anak, orangtua secara alami akan terhubung dengan anak-anaknya. Dengan belajar bersama, membaca bersama-sama, bermain game bersama-sama yang terjadi secara alami dan santai, orangtua membangun pengalaman yang membawa orangtua dengan anak-anaknya lebih dekat. Pengalaman bersama dengan anak-anaknya tersebut merupakan pengalaman belajar yang ditenun setiap hari akan menjadi benang-benang yang menghubungkan orangtua dengan anakanaknya dan akan membentuk ikatan yang kuat yang menyatukan seluruh keluarga. ${ }^{9}$

Selain dari itu, homeschooling juga menjadi pilihan yang dianggap tepat untuk memberikan pengajaran bagi anak-anak yang berbakat oleh banyak orangtua karena konten materi pembelajaran dan cara pemberian materinya disesuaikan dengan keadaan siswa yang bersangkutan. ${ }^{10}$

Dalam Undang-Undang Sisdiknas Nomor 20 Tahun 2003 Bab VI Pasal 13 ayat (1): "Bahwasannya jalur pendidikan terdiri atas pendidikan formal, nonformal, dan informal yang dapat saling melengkapi dan memperkaya. Dan pasal 13 ayat (2) bahwasannya pendidikan sebagaimana dimaksud pada ayat (1) diselenggarakan dengan sistem terbuka melalui tatap muka dan/atau melalui jarak jauh". ${ }^{11}$ Jadi, secara hukum kegiatan homeschooling dilindungi oleh undang-undang.

Homeschooling merupakan pendidikan berbasis rumah, yang memungkinkan anak berkembang sesuai dengan potensi diri mereka masing-masing. Gardner, seorang peneliti di Harvard University menyatakan bahwa kecerdasan merupakan kemampuan untuk menyelesaikan masalah, menciptakan produk yang berharga dalam satu atau beberapa lingkungan budaya masyarakat. ${ }^{12}$ Dan Gardner mengungkapkan kembali bahwa manusia tidak hanya memiliki satu kecerdasan melainkan sembilan jenis kecerdasan, yaitu: kecerdasan matematika, kecerdasan linguistik, kecerdasan musikal, kecerdasan, spasial, kecerdasan kinestetik, kecerdasan interpersonal, kecerdasan intrapersonal, kecerdasan natural, dan kecerdasan eksistensial. ${ }^{13}$

Salah satu kecerdasan yang penting distimulasi untuk perkembangan anak pada kehidupan selanjutnya adalah kecerdasan intrapersonal. Kecerdasan intrapersonal adalah kemampuan untuk mengamati atau mengerti maksud, motivasi, dan perasaan orang lain. ${ }^{14}$ Anak dengan kecerdasan intrapersonal memiliki banyak kecakapan, yakni kemampuan berempati dengan orang lain, kemampuan mengorganisasi sekelompok

\footnotetext{
${ }^{8}$ Aar dkk, Warna-Warni Homeschooling, (Jakarta: PT. Elex Media Komputindo, 2009), hlm 18

${ }^{9}$ Seto Mulyadi dkk., Psikologi Pendidikan, ..., hlm. 87

${ }^{10}$ Seto Mulyadi dkk., Psikologi Pendidikan, ..., hlm. 96

${ }^{11}$ Undang-Undang Sisdiknas Nomor 20 Tahun 2003 tentang Sistem Pendidikan Nasional, BAB VI, Pasal 13 ayat (1) dan (2)

${ }^{12}$ Tadkiroatun Musfiroh, Bermain Sambil Belajar dan Mengasah Kecerdasan Majemuk, (Jakarta: Departemen Pendidikan Nasional, Direktorat Jenderal Pendidikan Tinggi, Direktorat Pembinaan Pendidikan, Kependidikan, dan Perguruan Tinggi, 2005), hlm. 49

${ }^{13}$ Tadkiroatun Musfiroh, Bermain Sambil Belajar dan Mengasah Kecerdasan Majemuk, ..., hlm.

${ }^{14}$ Adi W Gunawan, Genius Learning Strategi, (Jakarta: PT. Gramedia Pustaka, 2006), hlm. 237 4 |Monica Nur Azizah dan Siti Shopiyah: Peran Pembelajaran Home Schooling, ...
} 
orang menuju suatu tujuan bersama, kemampuan mengenali atau membaca pikiran orang lain, kemampuan berteman, dan menjalin kontak. ${ }^{15}$ Jadi, anak yang bisa berinteraksi dengan baik adalah anak yang mempunyai mental kepribadian yang bagus terhadap lingkungan sekitar.

Dan sosialisasi terhadap sesama pun bisa dijalani apabila kesehatan mental sang anak serta kepribadiannya juga baik.

Sebagaimana Firman Allah Swt dalam QS. Al Hujurat [49] ayat 13 sebagai berikut:

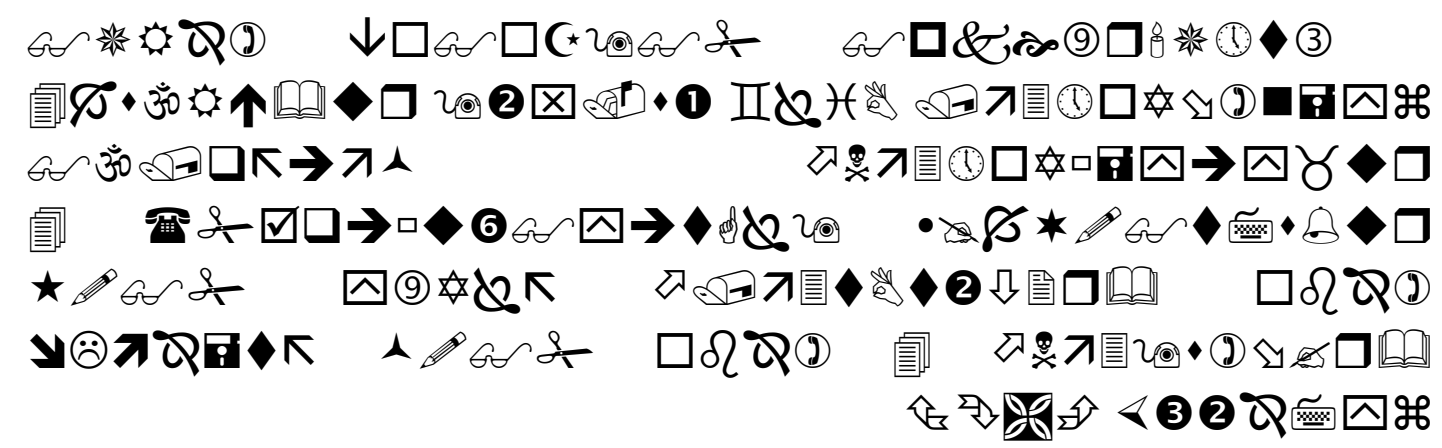

"Hai manusia, Sesungguhnya Kami menciptakan kamu dari seorang laki-laki dan seorang perempuan dan menjadikan kamu berbangsa - bangsa dan bersuku-suku supaya kamu saling kenal-mengenal. Sesungguhnya orang yang paling mulia diantara kamu di sisi Allah ialah orang yang paling taqwa diantara kamu. Sesungguhnya Allah Maha mengetahui lagi Maha Mengenal." (QS. Al Hujurat [49]: 13)

Kecerdasan dapat dicapai dengan tekun dan giat belajar dan berlatih. Namun, kecerdasan sejati hanya bisa didapatkan jika siswa menyadari bahwa ada faktor lain di luar dirinya yang membuat ia memiliki kecerdasan. Faktor yang pertama adalah Allah SWT., karena Allah SWT. yang telah menggerakan syaraf-syaraf di otak kita. Allah SWT. memfasilitasi manusia dengan indera-indera yang bisa difungsikan untuk eksplorasi ilmu pengetahuan di muka bumi ini. Faktor ini menjadi kunci manusia mendapatkan keutamaan kecerdasan sejati. Faktor yang kedua adalah kesadaran bahwa orang tua memiliki peran besar dalam usaha dan proses pencapaian kecerdasan. ${ }^{16}$ Jadi, yang dilakukan oleh manusia semuanya berkaitan dengan izin Allah SWT. terutama kecerdasan yang diberikan. Dan juga orang tua pun harus ikut membantu untuk meningkatkan kecerdasan sang anak.

Jadi, seorang anak yang mempunyai kesadaran diri yang tinggi akan selalu berusaha mengembangkan kemampuannya meskipun dengan kondisi dari sarana dan prasarana yang tidak mendukung. Selain itu, kecerdasan intrapersonal melibatkan model kerja yang efektif dari pendidik, dan kemampuan untuk menggunakan informasi tersebut untuk mengatur kehidupan anak juga.

15 Tadkiroatun Musfiroh, Pengembangan Kecerdasan Majemuk, (Jakarta: Universitas Terbuka, 2010), hlm. 73

16 Achjar Chalil dan Hudaya Latuconsina, Pembelajaran Berbasis Fitrah, (Jakarta: PT. Balai Pustaka (Persero), 2008), hlm. 114

5 |Monica Nur Azizah dan Siti Shopiyah: Peran Pembelajaran Home Schooling, ... 
Berdasarkan latar belakang masalah yang telah dikemukakan di atas, penulis merasa tertarik untuk melakukan penelitian dengan judul: Peran Pembelajaran Homeschooling Dalam Membentuk Kecerdasan Intrapersonal

\section{B. METODOLOGI PENELITIAN}

\section{Tempat dan Waktu Penelitian}

Pada penelitian skripsi ini, penulis melakukan penelitian di Fikar School yang bertempat di Komplek Puri Flamboyan Pesona E-3 No. 8 Rempoa, Kec. Ciputat Timur, Kota Tangerang Selatan, Provinsi Banten, Jawa Barat 15412.

\section{Sumber Data}

Sumber data yang digunakan dalam penelitian ini dibagi dalam dua kelompok, yaitu data primer dan data sekunder.

Primer

Sumber data primer adalah hasil karya penelitian yang otentik dan orisinil yang masih berkaitan langsung dengan tema penelitian yang dikaji, dimana sumber data ini merupakan deskriptif langsung tentang kenyataan yang dibuat individu yang mengemukakan teori pertama kali tentang problem kajian yang diteliti. ${ }^{1}$

Sekunder

Sumber data sekunder adalah tulisan-tulisan atau buku-buku dari berbagai disiplin ilmu yang membahas pokok permasalahan dalam pembahasan ini secara tidak langsung. ${ }^{2}$ Data sekunder yang akan penulis gunakan yaitu dokumen-dokumen, arsip, sumber buku dan buku-buku yang berkaitan dengan pembahasan.

\section{Teknik Pengumpulan Data}

Dalam Penelitian ini penulis menggunakan teknik analisis data antara lain wawancara, observasi, dan dokumentasi. Adapun penjelasannya sebagai berikut:

Wawancara

Wawancara adalah interaksi bahasa yang berlangsung antara dua orang dalam situasi saling berhadapan, yaitu yang melakukan wawancara meminta informasi atau ungkapan kepada orang yang diteliti yangberputar dis ekitar pendaat dan keyakinnannya. ${ }^{3}$ Wawancara merupakan teknik pengumpulan data yang dilakukan melalui tatap muka dan tanya jawab langsung dengan narasumber yang menjadi objek penelitian dan wawancara merupakan bagian yang penting dari pengumpulan data pada penelitian survey.

Dalam hal ini peneliti melakukan jenis wawancara terarah (guided interview) namun dengan menciptakan suasana yang santai sehingga penulis terlibat langsung secara mendalam dengan kehidupan subyek yang diteliti. Menurut Wiratna Sujarweni, wawancara terarah adalah dimana peneliti menanyakan kepada subyek yang diteliti

${ }^{1}$ Bambang Prasetyo dan Lina Miftahul Jannah, Metode Penelitian Kuantitatif; Teori dan Aplikasi, (Jakarta: PT. Raja Grafindo Persada, 2008), hlm. 152

${ }^{2}$ Bambang Prasetyo dan Lina Miftahul Jannah, Metode Penelitian Kuantitatif; Teori dan Aplikasi, ..., hlm. 153

3 Iskandar, Metode Penelitian Pendidikan dan Sosial (Kualitatif dan Kuantitatif), (Jakarta: Gaung Persada Press, 2008), hlm. 193.

6 |Monica Nur Azizah dan Siti Shopiyah: Peran Pembelajaran Home Schooling, ... 
berupa pertanyaan-pertanyaan yang menggunakan pedoman yang disiapkan sebelumnya. ${ }^{4}$

Dalam hal ini peneliti akan mewawancari beberapa subyek, antara lain:

1) Kepala sekolah: Zusrini S.Pd.

2) Manager Kesiswaan : Donny Mugia Pratoga, S.Pd.

3) Manager Penelitian dan Pengembangan (Litbang) : Agung Surya Gumelar, S.Pd, CHC, CPSM.

4) Manager HRD : Hazrat Avisenna, S. Sos.

Observasi

Menurut Burhan Bungin, Observasi atau pengamatan adalah metode pengumpulan data yang digunakan untuk menghimpun data penelitian melalui pengamatan dan pengindraan. ${ }^{5}$ Sedangkan menurutObservasi atau pengamatan merupakan suatu teknik atau cara mengumpulkan data dengan jalan mengadakan pengamatan terhadap kegiatan yang sedang berlangsung. ${ }^{6}$ Dengan observasi ini maka data yang akan diperoleh akan lebih lengkap, tajam dan sampai mengetahui pada tingkat makna dari setiap perilaku yang nampak. ${ }^{7}$

Dalam observasi ini, penulis mengamati terkait penerapan homeschooling dalam membentuk kecerdasan intrapersonal di Fikar School, yaitu penulis mengamati situasi sebelum dan sesudah proses pembelajaran, serta mengamati proses berlangsungnya pembelajaran homeschooling di sekolah tersebut.

Dokumentasi

Dokumentasi merupakan catatan atau karya seseorang tentang sesuatu yang sudah berlalu. Dokumen dapat berupa bentuk teks tertulis, artefacts, gambar maupun foto. ${ }^{8}$ Sedangkan menurut Wiratna Sujarweni, dokumentasi merupakan metode pengumpulan data kualitatif sejumlah besar fakta dan data tersimpan dalam bahan yang berbentuk surat, catatan harian, arsip foto, hasil rapat, cenderamata, jurnal kegiatan dan sebagainya. ${ }^{9}$

Dalam penelitian ini, dokumentasi dilakukan dengan mengumpulkan data-data yang berkaitan dengan dokumen dan arsip, seperti: Profil Fikar school dan visi misi sekolah, serta foto-foto yang berkaitan dengan pembelajaran dan sekolah.

\section{Teknik Analisis Data}

Analisis data dalam penelitian merupakan kegiatan yang dilakukan setelah seluruh data terkumpul. ${ }^{10}$ Proses analisis data dimulai dengan menelaah seluruh data yang tersedia dari berbagai sumber, yaitu angket, observasi, wawancara, pengamatan, dokumen, arsip, dan sebagainya. Teknik analisis data yang digunakan dalam penelitian ini adalah analisis data kualitatif, mengikuti konsep yang diberikan Miles and

\footnotetext{
${ }^{4}$ Wiratna Sujarweni, Metodologi Penelitian, (Yogyakarta: Pustaka Baru Press, 2014), hlm. 32

${ }^{5}$ Burhan Bungin, Penelitian Kualitatif, (Jakarta: Kencana, 2017), hlm. 118

${ }^{6}$ Sugiyono, Metode Penelitian Pendidikan, (Jakarta: Alfabeta, 2010), hlm. 66

${ }^{7}$ Sugiyono, Metode Penelitian Pendidikan, (Bandung: Alfabeta, 2016), hlm. 204

${ }^{8}$ Muri Yusuf, Metode Penelitian, (Jakarta: Prenadamedia Grup, 2019), hlm. 391.

${ }^{9}$ Wiratna Sujarweni, Metodologi Penelitian, (Yogyakarta: Pustaka Baru Press, 2014), hlm. 33.

10 Djunaidi Ghony dan Fauzan Almanshur, Metodologi Penelitian Pendidikan Pendekatan
} Kuantitatif, ..., hlm. 175 
Huberman dan Spradley. Aktivitas dalam analisis data, yaitu: data reduction, data display, dan conclusion drawing/verification. ${ }^{11}$

\section{a. Reduksi Data (Data Reduction)}

Mereduksi data berarti merangkum, memilih hal-hal yang pokok, memfokuskan pada hal-hal yang penting, dicari tema dan polanya. ${ }^{12}$ Menurut Muri Yusuf, reduksi data adalah suatu bentuk analisis yang mempertajam, memilih, memfokuskan, membuang, dan mengorganisasikan data dalam satu cara, dimana kesimpulan akhir dapat digambarkan dan diverifikasikan. ${ }^{13}$

Penulis akan melakukan pengumpulan data yang didapatkan dari wawancara ke beberapa informan, hasil dokumentasi berupa foto-foto, dokumen peraturan sekolah, serta dokumen-dokumen lainnya yang dapat menunjang penelitian ini. Setelah mengumpulkan data tersebut penulis akan memilah-milih data yang diperlukan serta membuang atau tidak memakai data yang tidak diperlukan. Sehingga data yang didapat tersusun dan terorganisir secara rapi.

\section{b. Penyajian Data (Data Display)}

Setelah data direduksi, maka langkah selanjutnya adalah mendisplaykan data. Melalui penyajian data tersebut, maka data dapat terorganisasikan, tersusun dalam pola hubungan, sehingga akan semakin mudah difahami. ${ }^{14}$

Dalam penelitian ini, penulis akan mendeskripsikan data dengan uraian naratif. Setelah data tereduksi, penulis akan menyajikan hasil observasi, wawancara dan dokumentasi yang telah dilakukan oleh penulis di Fikar School. Kemudian penulis menganalisis data sekunder dan data primer yang telah terkumpul dengan teknik analisis data deskriptif.

\section{c. Conclusion Drawing/Verification}

Langkah ketiga dalam analisis data kualitatif menurut Miles and Huberman adalah penarikan kesimpulan dan verifikasi. ${ }^{15}$ Setelah data tersusun rapi penulis akan menarik kesimpulan dan memverifikasi dari hasil penelitian tersebut.

\section{PEMBAHASAN DAN ANALISIS DATA PERAN PEMBELAJARAN HOMESCHOOLING DALAM MEMBENTUK KECERDASAN INTRAPERSONAL}

Pada bab ini, penulis akan memaparkan dan menganalisis hasil penelitian yang di dapat dari hasil observasi, wawancara, serta dokumentasi yang penulis kumpulkan di sekolah Fikar School.

1. Peran Pembelajaran Homeschooling.

Di Fikar School tidak sama dengan sekolah formal biasa. Jika di sekolah formal jam masuk sekolah mulai dari jam 07.00 WIB dan pulang pada jam 14.30 atau 15.00

\footnotetext{
${ }^{11}$ Sugiono, Metode Penelitian Pendidikan, (Bandung: Alfabeta, 2010), hlm. 377

${ }^{12}$ Wiratna Sujarweni, Metodologi Penelitian, (Yogyakarta: Pustaka Baru Press, 2014), hlm. 35

${ }^{13}$ Muri Yusuf, Metode Penelitian, (Jakarta: Prenadamedia Grup, 2019), hlm. 408

${ }^{14}$ Sugiono, Metode Penelitian Pendidikan, (Bandung: Alfabeta, 2010), hlm. 339

${ }^{15}$ Sugiono, Metode Penelitian Pendidikan, (Bandung: Alfabeta, 2010), hlm. 339
}

$8 \mid$ Monica Nur Azizah dan Siti Shopiyah: Peran Pembelajaran Home Schooling, ... 
bahkan sampai jam 16.00 WIB, kalau di Fikar School mereka belajar hanya dengan waktu 2 jam saja. Dari jam 09.00 WIB sampai jam 13.00 WIB dengan jeda waktu istirahat 1 jam dan juga di jeda dengan sholat dzuhur berjama'ah di musholla. Ketika pembelajaran di mulai, guru-guru tidak langsung memberikan materi yang diajarkan, tetapi melakukan ice breaking agar anak-anak semangat dalam memulai pembelajaran. Dan guru juga menerapkan apersepsi untuk memancing anak-anak agar dapat langsung masuk ke dalam materi yang akan di bahas.

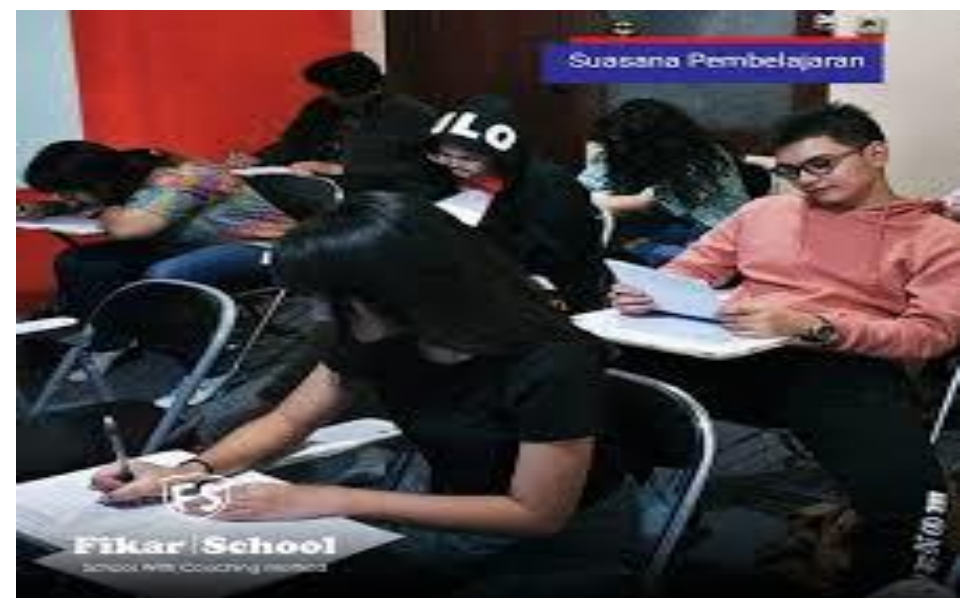

Gambar 4.1

Kegiatan Pembelajaran di Kelas Fikar School

Lalu untuk pembagian kelas sama seperti di sekolah formal. Ada tingkatan jenjang pendidikannya, seperti SD kelas 1-6, SMP kelas 7-9, dan SMA kelas 10-12. Di Fikar School juga ada kelas jurusan yang di mulai dari tingkat SMA yaitu jurusan IPA dan IPS. Ini adalah sebuah pernyataan dari hasil wawancara kepada Kepala Sekolah Fikar School yang bernama Bu Zusrini, S. Pd. ${ }^{16}$ Pernyataan tersebut selaras dengan hasil wawancara dari Manager Kesiswaan Fikar School yang bernama Pak Donny Mugia Prayogo, S. Pd ${ }^{17}$ dan juga dari Manager HRD Fikar School yang bernama Pak Hazrat Avisenna, S. Sos. ${ }^{18}$

Kurikulum di sekolah formal dan homeschooling Fikar School ada sedikit perbedaan. Kurikulum di sekolah menggunakan kurikulum 2013 (K13). Sedangkan di Fikar School ini mempunyai 2 kurikulum yang diterapkan dalam pembelajarannya, yaitu kurikulum 2013 (K13) dan kurikulum Cambridge. Kemudian pembagian kelasnya di pisah. Untuk anak yang ingin melanjutkan sekolah atau melanjutkan pendidikannya ke luar negeri, mereka lebih memilih kepada kurikulum Cambridge. Karena kurikulum ini pembelajarannya full english yang materinya lebih mengdepankan konseptual tentang kehidupan sehari-hari. Ini adalah sebuah pernyataan dari hasil wawancara

\footnotetext{
${ }^{16}$ Wawancara dengan Kepala Sekolah, di Fikar School, Zusrini, Rempoa, pada tanggal 13 Agustus 2019.

17 Wawancara dengan Manager Kesiswaan, di Fikar School, Donny Mugia Prayogo, Rempoa, pada tanggal 13 Agustus 2019.

${ }^{18}$ Wawancara dengan Manager HRD, di Fikar School, Hazrat Avisenna, Rempoa, pada tanggal 14 Agustus 2019.
}

9 | Monica Nur Azizah dan Siti Shopiyah: Peran Pembelajaran Home Schooling, ... 
dengan Manager Kesiswaan yaitu Pak Donny Mugia Prayogo, S. Pd. ${ }^{19}$ Dan pernyataan ini pun selaras dengan hasil wawancara dari Manager Litbang yaitu Pak Agung Surya Gumelar, S. Pd, CHC., CPSM. ${ }^{20}$

Di sekolah Fikar School tidak semuanya anak-anaknya normal, tetapi ada anak yang berkebutuhan khusus. Dalam pembelajaran ini, tidak ada pengkhususan kelas untuk ABK tetapi digabungkan menjadi satu dengan anak-anak yang normal. Agar dapat mendapatkan dan mengikuti pelajaran dengan baik, maka ABK ini akan di dampingi oleh yang namanya shadow teacher.

Shadow teacher adalah guru pendamping untuk anak yang memiliki kebutuhan khusus. Jadi ketika belajar, shadow teacher ini yang akan selalu ada untuk memahami pelajaran yang di sampaikan. Ini adalah sebuah pernyataan dari hasil wawancara dengan Pak Hazrat Avisenna, S. Sos. ${ }^{21}$ Dan pernyataan ini pun selaras dengan hasil wawancara dari Pak Agung Surya Gumelar, S. Pd, CHC., CPSM. ${ }^{22}$

Lalu untuk pernyataan dari hasil wawancara Kepala Sekolah Fikar School, yaitu bu Zusrini, S. Pd, bahwa "Semua anak pasti mempunyai keunikan dan kebutuhannya masing-masing. Seperti interaksi kurang, apa yang dilakukan anak tersebut harus terus-menerus untuk diperintahkan, memiliki tugas yang banyak, tidak mau untuk diajarkan guru yang formal itu termasuk kebutuhan khusus, bukan hanya seperti ABK autis dan lainnya yang membutuhkan perhatian lebih". ${ }^{23}$

Lalu untuk pernyataan dari hasil wawancara dengan Manager Kesiswaan, Pak Donny Mugia Prayogo, S. Pd, beliau mengungkapkan bahwa "Semua tipe anak itu formal, sehat, dan pintar. Memang di Fikar School ada salah satu anak ABK nya, tetapi ia dimasukkan dengan kelas normal dan lingkungan normal. Dan melihat perkembangan saat ini bahwasannya anak ABK ini sudah terlihat seperti normal karena seseorang akan terpengaruh dengan lingkungannya". ${ }^{24}$

Di sekolah formal mendapatkan nilai akhir dengan mendapatkan rapor ketika telah mengikuti Ujian Akhir Semester (UAS), di Fikar School tidak mendapatkan itu semua di akhir, melainkan setiap hari. Penilaian anak dilakukan setiap hari, dan setiap hari pun akan dibuatkan rapor dan akan dikirimkan via e-mail pada sore hari kepada orang tua masing-masing anak. Ini disebut dengan DPR (Dairy Progress Report). Ungkapan ini hasil dari wawancara dengan Manager Litbang Fikar School, Pak Agung Surya Gumelar, S. Pd, CPC., CPSM. ${ }^{25}$

\footnotetext{
19 Wawancara dengan Manager Kesiswaan, di Fikar School, Donny Mugia Prayogo, Rempoa, pada tanggal 13 Agustus 2019.

${ }^{20}$ Wawancara dengan Manager Penelitian dan Pengembangan, di Fikar School, Agung Surya Gumelar, Rempoa, pada tanggal 8 Agustus 2019.

${ }^{21}$ Wawancara dengan Manager HRD, di Fikar School, Hazrat Avisenna, Rempoa, pada tanggal 13 Agustus 2019.

22 Wawancara dengan Manager Penelitian dan Pengembangan, di Fikar School, Agung Surya Gumelar, Rempoa, pada tanggal 8 Agustus 2019.

${ }^{23}$ Wawancara dengan Kepala Sekolah, di Fikar School, Zusrini, Rempoa, pada tanggal 13 Agustus 2019.

${ }^{24}$ Wawancara dengan Manager Kesiswaan, di Fikar School, Donny Mugia Prayogo, Rempoa, pada tanggal 13 Agustus 2019.

${ }^{25}$ Wawancara dengan Manager Penelitian dan Pengembangan, di Fikar School, Agung Surya Gumelar, Rempoa, pada tanggal 8 Agustus 2019.
}

10 | Monica Nur Azizah dan Siti Shopiyah: Peran Pembelajaran Home Schooling, ... 


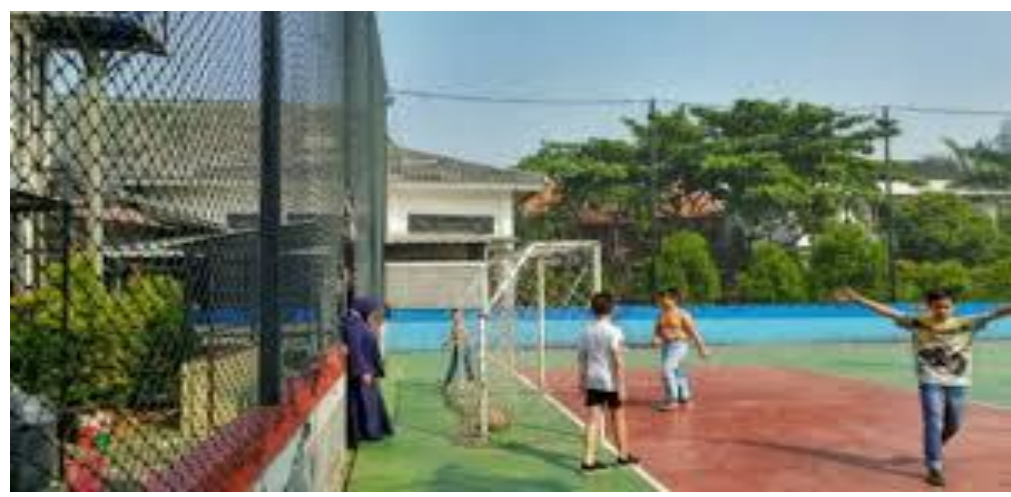

Gambar 4.2

Lapangan Futsal

Dari segi bangunan atau sarana prasarana homeschooling Fikar School dan sekolah formal jelas berbeda sekali. Untuk sekolah formal, dari segi bangunan sudah besar, karena mempunyai beberapa kelas yang sangat memadai dan menampung siswa-siswi yang diisi perkelasnya mencapai 30-40 orang perkelas. Sekolah formal juga mempunyai fasilitas yang lengkap. Seperti, labolatorium, ruang komputer, perpustakaan, lapangan futsal, musholla, dan lain sebagainya. Sedangkan di homeschooling Fikar School fasilitas tidak terlalu lengkap, tapi mempunyai lapangan futsal, musholla, lapangan bilyard, lapangan tenis, dan sesuai dengan yang dibutuhkan oleh anak-anak akan berusaha di lengkapi oleh sekolah Fikar School tersebut. Ini adalah pernyataan hasil dari wawancara dengan Kepala Sekolah Fikar School Bu Zusrini, ${ }^{26}$ S. Pd, Manager Litbang Pak Agung Surya Gumelar, S. Pd, CHC., CPSM, ${ }^{27}$ dan Manager HRD Pak Hazrat Avisenna, S. Sos. ${ }^{28}$

Dari segi target pembelajaran homeschooling Fikar School dan sekolah formal berbeda. Untuk sekolah formal sesuai dengan silabus dan mengikuti KI dan KD dari pemerintah, sedangkan homeschooling Fikar School sesuai dengan anak. Karena di homeschooling lebih mengedepankan karakter dibandingkan dengan akademik. Pernyataan ini disampaikan dari hasil wawancara dengan Manager Kesiswaan Fikar School Pak Donny Mugia Prayogo, S. Pd. ${ }^{29}$ Pernyataan tersebut selaras dengan hasil wawancara dengan Manager HRD Fikar School Pak Hazrat Avisenna, S. Sos. ${ }^{30}$ Kemudian pernyataan dari hasil wawancara dengan kepala sekolah Fikar School bu Zusrini, S. Pd ${ }^{31}$ dan Manager Litbang Pak Agung Surya Gumelar, S. Pd, CHC.

Dalam pembelajaran homeschooling di Fikar School ini pasti memiliki keluh kesah tersendiri bagi penyelenggaranya. Adanya faktor pendukung dan penghambat

${ }^{26}$ Wawancara dengan Manager Kepala Sekolah, di Fikar School, Zusrini, Rempoa, pada tanggal 13 Agustus 2019.

27 Wawancara dengan Manager Penelitian dan Pengembangan, di Fikar School, Agung Surya Gumelar, Rempoa, pada tanggal 8 Agustus 2019.

${ }^{28}$ Wawancara dengan Manager HRD, di Fikar School, Hazrat Avisenna, Rempoa, pada tanggal 14 Agustus 2019.

29 Wawancara dengan Manager Kesiswaan, di Fikar School, Donny Mugia Prayogo, Rempoa, pada tanggal 13 Agustus 2019.

${ }^{30}$ Wawancara dengan Manager HRD, di Fikar School, Hazrat Avisenna, Rempoa, pada tanggal 14 Agustus 2019.

${ }^{31}$ Wawancara dengan Manager Kepala Sekolah, di Fikar School, Zusrini, Rempoa, pada tanggal 13 Agustus 2019.

11 | Monica Nur Azizah dan Siti Shopiyah: Peran Pembelajaran Home Schooling, ... 
dalam mendirikan Fikar School. Menurut hasil wawancara dengan Manager Penelitin dan Pengembangan (Litbang) Pak Agung Surya Gumelar, S. Pd, CPC., CPSM., faktor pendukung dari penyelenggara pembelajaran homeschooling, yaitu: mempunyai fasilitas yang lengkap seperti mempunyai musholla serta adanya lapangan badminton, memiliki suasana lingkungan yang kondusif untuk belajar, mempunya metode culture habit yang sangat mendukung, dan yang terakhir adalah mempunyai team yang sangat solid dalam kerjasama itu yang terpenting. Sedangkan faktor penghambatnya, yaitu: tempat pembelajaran kurang luas, selalu mengikuti permintaan anak seperti sebelum memulai pelajaran anak-anak ingin bermain games terlebih dahulu dan baru bisa untuk memulai pembelajaran, dan yang yang terlihat jelas adalah lingkungan yang kurang luas. ${ }^{32}$

Metode coaching dapat membantu dengan cepat pertumbuhan kecerdasan intrapersonal yang dimiliki masing-masing anak dan sesuai dengan keinginan minat dan bakatnya yang akan dikembangkan. Seperti, keinginan anak untuk menjadi seorang pelukis, maka coaching tersebut akan mengajarkan dan menuntun anak tersebut untuk mempelajari lebih dalam cara-cara melukis dengan baik dan benar. Dan ketika pembelajaran formal, coaching dibantu oleh guru mata pelajaran untuk memberikan gambaran atau bayangan terhadap suatu mata pelajaran tersebut menjadi sesuatu yang dapat untuk di lukis.

Jadi culture habit di sini dapat membuat anak lebih menjadi diri yang mandiri, dan lebih menggali kepada pembentukan karakternya. Anak-anak di Fikar School lebih di sekolah tersebut.

\section{KESIMPULAN}

Berdasarkan hasil penelitian yang terlaksana di sekolah Fikar School bahwa Peran Pembelajaran Homeschooling sangat efektif dan berdampak positif dalam Membentuk Kecerdasan Intrapersonal pada anak-anak homeschooling. Hal ini dapat dibuktikan dengan hasil penelitian, yaitu bahwa di Fikar School sangat menerapkan pada muatan karakter anak dan itu berdampak kepada diri masing-masing anak tersebut untuk dapat mengetahui sejauh mana kemampuan yang dimiliki dan kesadaran akan minat dan bakat mereka. Dengan proses pembelajaran seperti culture habit ini dapat memberikan pengaruh yang baik kepada kecerdasan intrapersonal anak, sehingga dapat membentuk karakter yang baik dan menjadikan budaya anak untuk mandiri di manapun lingkungan dia berada. Dari hasil penelitian, penulis menemukan hal baru yaitu pembelajaran dengan metode coaching. Dengan adanya metode ini, anak-anak di homeschooling Fikar School akan berkembang sesuai dengan potensi mereka masing-masing.

32 Wawancara dengan Manager Penelitian dan Pengembangan, di Fikar School, Agung Surya Gumelar, Rempoa, pada tanggal 8 Agustus 2019.

12 | Monica Nur Azizah dan Siti Shopiyah: Peran Pembelajaran Home Schooling, ... 


\section{E. DAFTAR PUSTAKA}

Al-Qur'an dan Terjemah. Jakarta: PT. Sygma Examedia Arkanleema. 2016

Aar dk. Warna-Warni Homeschooling. PT. Elex Media Komputindo. 2009

Al-Tabany, Trianto Ibnu Badar. Mendesain Model Pembelajaran Inovatif, Progresif, dan Kontekstual. Prenadamedia Group. 2014

Anshori, Muslich dan Sri Iswati. Metodologi Penelitian Kuantitatif. Airlangga University Press. 2009

Arikunto, Suharsimi. Prosedur Penelitian Suatu Pendekatan Praktek. Rineka Cipta. 1998

Chalil, Achjar, dan Hudaya Latuconsina. Pembelajaran Berbasis Fitrah. PT. Balai Pustaka (Persero). 2008

Dayakisni, Tri dan Salis Yuniardi. Psikologi Lintas Budaya. UPT Penerbitan Universitas Muhammadiyah Malang. 2008

Fathiyaturrahmah dan Safrudin Edi Wibowo. Peranan Ibu dalam Pendidikan Anak dalam Perspektif Al-Qur'an. Madania Center Press. 2008

Ghony, Djunaidi dan Fauzan Almanshur. Metodologi Penelitian Pendidikan Pendekatan Kuantitatif. UIN-Malang Press. 2016

Gordon, Claire dan Lynn Huggins-Cooper. Meningkatkan 9 Kecerdasan Anak. PT. Bhuana Ilmu Populer. 2013

Gunawan, Adi W. Genius Learning Strategi. PT. Gramedia Pustaka. 2006

Hanaco, Indah. I Love Homeschooling. PT. Gramedia Pustaka Utama. 2012

Helmawati. Mendidik Anak Berprestasi Melalui 10 Kecerdasan. PT. Remaja Rosdakarya. 2018 Pendidik Sebagai Model. PT. Remaja Rosdakarya. 2016

Hoerr, Thomas R. Buku Kerja Multiple Intelligences, PT. Mizan Pustaka, 2007

Https://kbbi.kemdikbud.go.id/entri/membentuk

Https://kbbi.kemdikbud.go.id/entri/peran

Sabri, M. Alisuf. Psikologi Pendidikan Berdasarkan Kurikulum Nasional. Pedoman Ilmu Jaya. 1996

Saebani, Beni Ahmad dan Yana Sutisna. Metodologi Penelitian. CV Pustaka Media. 2018

13 | Monica Nur Azizah dan Siti Shopiyah: Peran Pembelajaran Home Schooling, ... 
Sanjaya, Wina. Strategi Pembelajaran Berorientasi Standar Proses Pendidikan. Prenadamedia Group. 2016

Sarwono, Sarlito W. Psikologi Remaja. PT. Rajagrafindo Persada. 2016

Satiadarma, Monty P. \& Fidelis E. Waruwu. Mendidik Kecerdasan. Pustaka Populer Obor. 2003

Soekanto, Soerjono dan Budi Sulistyowati. Sosiologi Suatu Pengantar. PT. RajaGrafindo Persada. 2015

Sugiyono. Metode Penelitian Kuantitaitif, Kualitatif, dan R\&D. Alfabeta. 2016 , Metode Penelitian Pendidikan. Alfabeta. 2010

Suhardono, Edy. Teori Peran. PT. Gramedia Pustaka Utama. 1994

Sukmadinata, Nana Syaudih. Metode Penelitian Pendidikan. PT. Remaja Rosdakarya. 2010

Susanto, Ahmad. Teori Belajar dan Pembelajaran di Sekolah Dasar. Prenadamedia Group. 2013

Suyono dan Hariyanto. Belajar dan Pembelajaran. PT. Remaja Rosdakarya. 2017

Syam, Nina W. Psikologi Sebagai Akar Ilmu Komunikasi. Simbiosa Rekatama Media. 2011

Undang-Undang Republik Indonesia No 20 Tahun 2003 tentang Sistem Pendidikan Nasional

Uno, Hamzah B. dan Masri Kuadrat Umar. Mengelola Kecerdasan Dalam Pembelajaran. PT. Bumi Aksara. 2009

Uno, Hamzah B. Perencanaan Pembelajaran. PT. Bumi Aksara. 2010

Yaumi, Muhammad dan Nurdin Ibrahim. Pembelajaran Berbasis Kecerdasan Jamak (Multiple Intelligences). Prenadamedia Group. 2016

Yusuf, Muri. Metode Penelitian Kuantitatif, Kualitatif, dan Penelitian Gabungan. KENCANA. 2017 